Locomotion response of airborne, ambulatory and aquatic insects to thermal stimulation using piezoceramic microheaters

This article has been downloaded from IOPscience. Please scroll down to see the full text article.

2011 J. Micromech. Microeng. 21125002

(http://iopscience.iop.org/0960-1317/21/12/125002)

View the table of contents for this issue, or go to the journal homepage for more

Download details:

IP Address: 141.211.173.82

The article was downloaded on 06/04/2012 at 15:57

Please note that terms and conditions apply. 


\title{
Locomotion response of airborne, ambulatory and aquatic insects to thermal stimulation using piezoceramic microheaters
}

\author{
Karthik Visvanathan and Yogesh B Gianchandani \\ Department of Mechanical Engineering, University of Michigan, Ann Arbor, MI, USA \\ E-mail:vkarthik@umich.edu
}

Received 28 March 2011, in final form 20 September 2011

Published 3 November 2011

Online at stacks.iop.org/JMM/21/125002

\begin{abstract}
This paper reports the locomotion response of airborne, ambulatory and aquatic insects to thermal stimulation. A finite element model has been developed to predict the variation of insect-stimulator interface temperature with input power. Piezothermal stimulators have been fabricated from lead zirconate titanate (PZT) using a batch mode micro ultrasonic machining process. Typical sizes range from $200 \mu \mathrm{m}$ to $3.2 \mathrm{~mm}$. For PZT stimulators, the temperature and thermal efficiency reach the maximum value around the resonance frequency which is typically in the range of $650 \mathrm{kHz}$ to $47 \mathrm{MHz}$. Experiments have been conducted on green June beetles (GJBs), Madagascar hissing roaches and green diving beetles (GDBs) in order to show the versatility of the proposed technique. The stimulators have been implanted near the antennae of the GJBs and on either side of the thorax of the Madagascar hissing roaches and GDBs, respectively. In all cases, the insects move away from the direction of the actuated stimulator. The left and right turns are statistically similar. Thermal stimulation achieves an overall success rate of $78.7 \%, 92.8 \%$ and $61.6 \%$ in GJBs, roaches and GDBs, respectively. On average, thermal stimulation results in an angle turn of about $13.7^{\circ}-16.2^{\circ}$ on GJBs, $30^{\circ}-45^{\circ}$ on the roaches and $30^{\circ}-50^{\circ}$ on GDBs. The corresponding average input power is 360,330 and $100 \mathrm{~mW}$ for GJBs, roach and GDBs, respectively. Scaling limits of the PZT stimulators for operating these stimulators are also discussed.
\end{abstract}

(Some figures in this article are in colour only in the electronic version)

\section{Introduction}

Developments in digital electronics, communications and microfabrication over the past decades have spurred research on autonomous micro vehicles. The goal of these micro vehicles is to provide an inexpensive platform for carrying various sensors and actuators for military applications such as surveillance, radiation and chemical spill mapping and for civil applications such as aid in search and rescue operations, wildlife monitoring, etc.

Interest in micro air-vehicles (MAVs) has existed at least since the 1990s. One of the earliest battery powered MAVs were developed by Aero Vironment Inc. [1]. Later, fixed wing prototypes were developed by Lockheed Sanders [2] and Naval Research Laboratory [3], respectively. A flexible wing MAV prototype was designed by Ifju et al [4]. There have also been efforts at developing MAVs that use internal combustion engines [5] and solar power [6]. With more emphasis on miniaturization, and inspiration from insects, micro vehicles based on the flapping wing mechanism were reported [7-11]. A biologically inspired micro vehicle capable of aerial and terrestrial locomotion was reported in [12]. In addition to the aerial and terrestrial micro vehicles, underwater micro vehicles based on ionic polymer metal composite actuator were reported in $[13,14]$. 
Numerous studies have been directed at the locomotion of various species of insects [15]. Insects have highly efficient and effective means of locomotion and may provide the inspiration for improvements of locomotion range and payload capacity. For example, the role of the motion sensitive horizontal cells in the lobula plate of the fly in controlling the yaw torque generated was studied in $[16,17]$. The dependence of the flight stability during maneuvers of hawk moth on the mechanosensory input from the antenna was reported by Sane et al [18]. An FM radio telemetry device, weighing $0.4 \mathrm{~g}$, was developed to record the muscle potential from a free flying moth [19]. Similarly, a radio-frequency system with a shape memory alloy micro electrode was reported for neural recording of freely moving insects such as cockroaches [20]. Mohseni et al described an FM biopotential recording system for dorsal muscles of a giant spinx moth fabricated on a foldable, lightweight polyimide substrate [21].

There have also been preliminary studies of stimulating locomotion in land and airborne insects. Electroneural stimulation by implanted electrodes is the most common technique that has been explored for stimulating motion. Moore et al reported the steering of Madagascar hissing roaches with minimally invasive electrical stimuli to the basal region of either antennae or cerci [22]. Similarly, electrical stimulation of the muscles in the hind legs of Periplanata americana was reported in [23]. The effectiveness of electrical stimulation of antenna of $P$. americana for controlling locomotion was reported in [24]. A micromachined bioelectronic neuromuscular interface for flight control of Manduca sexta has been developed in [25]. A biorobotic platform intended to explore the emergent behaviors resulting from the coupling of a tethered fly and a wheeled robot was reported in [26]. An implantable flight control microsystem consisting of neural, muscular and visual stimulators for locomotion control of Cotinis texana was reported in [27]. Successful flight control of giant beetles (Mecynorhina torquata) was also demonstrated by direct neural stimulation of optic lobes [28]. The behavioral response of tiger beetles (Cicindela marutha) to trains of bat-like ultrasonic pulses was reported [29], but was successful only for flight initiation, not directional control.

Recent advances in microfabrication have made it possible to make sensors and actuators weighing less than a gram that can be attached as a 'backpack'. Further, surgical implantation of microsystems during the late pupal stage in hawk moths has been demonstrated by Paul et al [30]. A microsystem consisting of radio-frequency receiver assembly, a microbattery and an electroneural stimulator has been developed by Sato et al for electroneural flight control of $M$. torquata $[31,32]$.

Apart from locomotion training of insects, microthermal stimulation can also be used as a method of punishment in operant conditioning studies of insects [33]. This paper ${ }^{1}$ presents an effort at thermal stimulation using microheaters, which exploits the natural propensity of insects to escape fire, to initiate and guide the direction of their locomotion.

1 Portions of this paper have been published in conference abstract form in $[34,35]$.

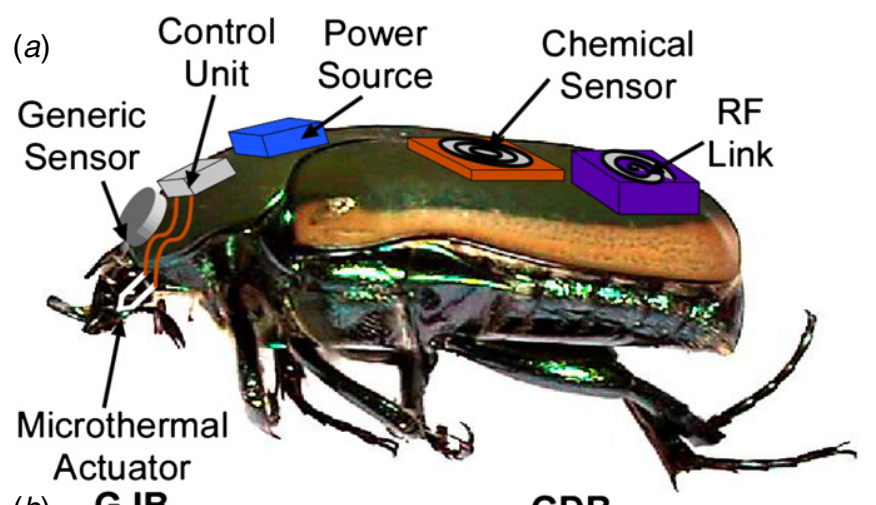

(b) $\mathbf{G J B}$

GDB

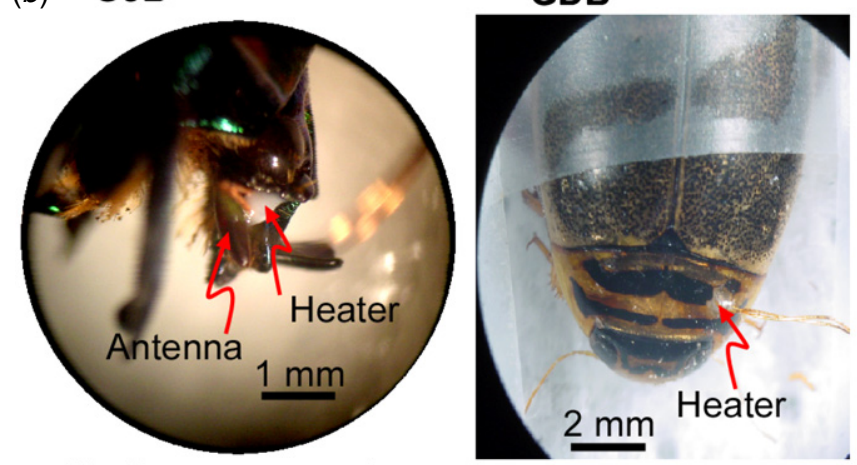

(c) Madagascar roach

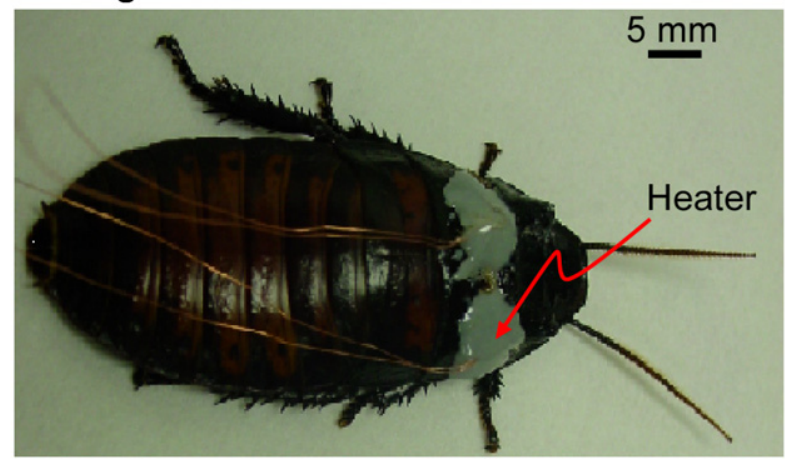

Figure 1. (a) Concept of instrumented insect. (b) Enlarged side view of the head of the beetle with the thermal stimulators near the antenna of the GJB. (c) Photograph of the Madagascar hissing roaches with implanted thermal stimulators. (d) Photograph of the GDB with an implanted thermal stimulator.

Preliminary studies suggest that insects experience discomfort at temperatures $>43{ }^{\circ} \mathrm{C}$ [36]. This technique is potentially widely applicable across different species of insects due to its independence from any specific neurological or physiological structures of the concerned insect. In order to show the versatility of the proposed technique, experiments are conducted on the green June beetles (GJBs) (Cotinis nitida), Madagascar hissing roaches (Gromphadorhina portentosa) and green diving beetles (GDBs) (Thermonectus) (figure 1). This work explores the feasibility of lead zirconate titanate (PZT) based piezothermal stimulators and analyzes their performance for the locomotion control of insects.

Section 2 describes the design and fabrication of the stimulators used in the experiments. A finite element model has been described for prediction of temperature rise at the stimulator-insect interface for different input powers. 
Table 1. Material properties used in the finite element simulation of interface temperature generated for various input powers.

\begin{tabular}{|c|c|}
\hline Beetle tissue properties & Epoxy properties \\
\hline Initial temp., $T_{1}=295 \mathrm{~K}$ & Initial temp., $T_{2}=295 \mathrm{~K}$ \\
\hline Density, $\rho_{1}=1100 \mathrm{~kg} \mathrm{~m}^{-3}$ & Density, $\rho_{2}=1096 \mathrm{~kg} \mathrm{~m}^{-3}$ \\
\hline Heat capacity, $c_{1}=3700 \mathrm{~J} \mathrm{~kg}^{-1} \mathrm{~K}^{-1}$ & Heat capacity, $c_{2}=1100 \mathrm{~J} \mathrm{~kg}^{-1} \mathrm{~K}^{-1}$ \\
\hline Thermal conductivity, $k_{1}=1 \mathrm{~W} \mathrm{~m}^{-1} \mathrm{~K}^{-1}$ & Thermal conductivity, $k_{2}=0.25 \mathrm{~W} \mathrm{~m}^{-1} \mathrm{~K}^{-1}$ \\
\hline Copper wire properties & PZT-5A properties \\
\hline Initial temp., $T_{3}=295 \mathrm{~K}$ & Initial temp., $T_{4}=295 \mathrm{~K}$ \\
\hline Density, $\rho_{3}=8700 \mathrm{~kg} \mathrm{~m}^{-3}$ & Density, $\rho_{4}=7650 \mathrm{~kg} \mathrm{~m}^{-3}$ \\
\hline Heat capacity, $c_{3}=385 \mathrm{~J} \mathrm{~kg}^{-1} \mathrm{~K}^{-1}$ & Heat capacity, $c_{4}=350 \mathrm{~J} \mathrm{~kg}^{-1} \mathrm{~K}^{-1}$ \\
\hline Thermal conductivity, $k_{3}=400 \mathrm{~W} \mathrm{~m}^{-1} \mathrm{~K}^{-1}$ & Thermal conductivity, $k_{4}=1.5 \mathrm{~W} \mathrm{~m}^{-1} \mathrm{~K}^{-1}$ \\
\hline
\end{tabular}
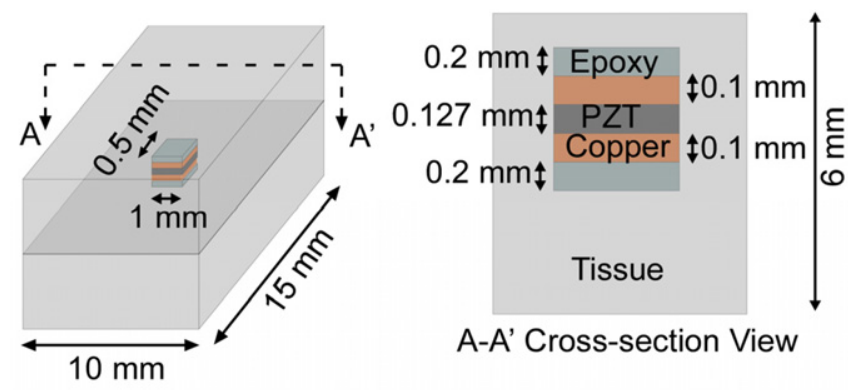

A-A' Cross-section View

Figure 2. Schematic of the model used in the finite element simulations for predicting insect-stimulator interface temperature.

Section 3 presents the experimental results. The initial part describes the characterization of piezothermal stimulators. The latter portion describes the experiments on thermal stimulation of locomotion in GJBs, Madagascar hissing roaches and GDBs. Finally, scaling limits of the piezothermal stimulators are discussed in section 4.

\section{Design and fabrication}

Four different kinds of PZT-based microstimulators (P1, P2, P3, P4) are investigated. The PZT-based stimulators generate heat due to dielectric losses in the PZT and the damping of ultrasonic waves in PZT and surrounding medium [37]. The PZT stimulators are believed to be suitable for this application as they have high impedance even at thicker crosssection (hundreds of microns), which is required to provide structural rigidity to withstand the forces during implantation and bonding and reduce parasitic losses in the connecting wires. PZT-5A is used in this study because of its higher Curie temperature $\left(\approx 350{ }^{\circ} \mathrm{C}\right)$, which allows higher working temperatures. Moreover, the piezoelectric constant $\left(d_{31}\right)$ and relative dielectric constant of PZT-5A show lower temperature sensitivity as compared to other PZT materials such as PZT-5H [38].

A finite element simulation model is developed to predict the input power required to achieve the target temperature by the stimulators. The steady state heat conduction model in COMSOL Multiphysics ${ }^{\circledR}$ is used in these simulations. The simulations are performed for a rectangular PZT-5A piezothermal stimulator $\left(1 \times 0.5 \times 0.127 \mathrm{~mm}^{3}\right)$ used in the

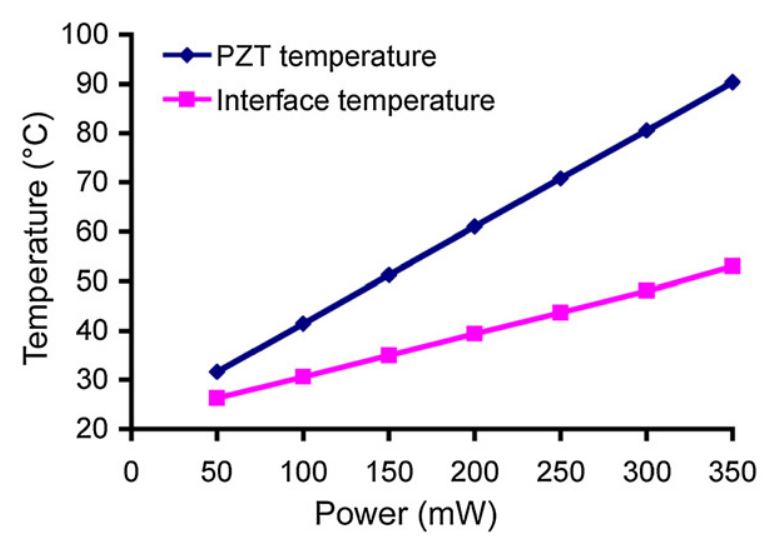

Figure 3. Finite element simulation results showing the maximum temperature in the PZT and the temperature at the tissue interface as a function of varying input power.

experiments on GJB (figure 2). Each stimulator is assumed to be surrounded by $100 \mu \mathrm{m}$ thick copper wire and $200 \mu \mathrm{m}$ thick non-conductive epoxy on both sides for insulation. The stimulator is assumed to be implanted in the tissue. In order to reduce the complexity of the model, the insect body is modeled using a $15 \times 10 \times 6 \mathrm{~mm}^{3}$ cuboid. Because of high impedance, Joule heating can be neglected. All input power delivered is assumed to be converted into heat-either within the PZT element or within the surrounding tissue. The tissue boundaries exposed to surroundings are assumed to be at the room temperature of $295 \mathrm{~K}$. The material properties used in the simulation are listed in table 1.

Figure 3 shows the simulation results for the variation of the maximum temperature in the stimulator and the average temperature at the insect-stimulator interface for varying input power. The simulations suggest that the target temperature $\left(\approx 43{ }^{\circ} \mathrm{C}\right)$ is achieved for the input power of $250 \mathrm{~mW}$. At this input power, the maximum temperature in the stimulator is $70{ }^{\circ} \mathrm{C}$.

The specifications of the stimulators used in the experiments are given in table 2. Circular PZT stimulators (P1/P4) are fabricated by ultrasonic micromachining of the piezoelectric elements from a PZT-5A plate (figure 4) [39]. The fabrication of piezoelectric stimulators is a twostep process. A negative image of the desired pattern is micromachined on a stainless steel substrate using micro electro-discharge machining. The pattern formed is then 


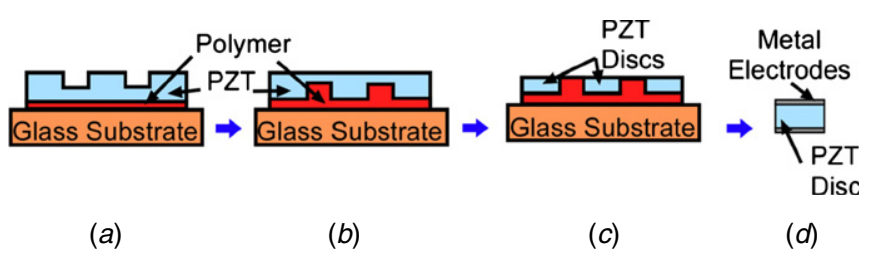

Figure 4. Ultrasonic machining for PZT stimulators. (a) Bond a PZT plate to a glass substrate and USM to pattern it. (b) Release PZT plate from glass substrate 1, then flip and bond it to glass substrate 2. (c) Lap to remove extra PZT plate thickness and release PZT discs from glass substrate 2. $(d)$ Micro-machined PZT.

Table 2. Comparison chart for different types of piezothermal stimulators used in the experiment.

\begin{tabular}{llll}
\hline & Shape & Dim. (mm) & Property \\
\hline P1 & $\bigcirc$ & $\Phi=3.2 ; h=0.2$ & $C=0.65 \mathrm{nF}$ \\
P2 & & $1 \times 3 \times 0.127$ & $C=0.37 \mathrm{nF}$ \\
P3 & & $1 \times 0.5 \times 0.127$ & $C=0.06 \mathrm{nF}$ \\
P4 & $\bigcirc$ & $\Phi=0.2 ; h=0.04$ & $C=0.012 \mathrm{nF}$ \\
\hline
\end{tabular}

transferred to the PZT-5A plate using ultrasonic machining with the help of tungsten carbide abrasive slurry. The plate is then flipped over and lapped from behind to release the pattern imprinted by the steel tool. A $500 \mathrm{~nm}$ thick gold metal layer is sputtered onto the PZT disks to form the electrodes. Thin copper wires (gauge $\approx 38$, length $\approx 40 \mathrm{~cm}$, resistance $\approx 0.2 \Omega$ ) are connected to the PZT disks using conductive epoxy followed by an insulating layer of nonconductive epoxy.

The rectangular PZT stimulators $(\mathrm{P} 2 / \mathrm{P} 3)$ are made by dicing a $0.127 \mathrm{~mm}$ thick PZT-5A plate into the required dimensions. The electrical connections are provided by connecting copper wires (gauge $\approx 44$ ) using conductive epoxy followed by a coating of non-conductive epoxy.

\section{Experimental results}

Section 3.1 describes the experiments performed to evaluate suitable operating frequencies for the piezothermal stimulators. Section 3.2 describes the thermal stimulation results on GJBs, Madagascar hissing roaches and GDBs.

\subsection{Characterization of the piezothermal stimulator}

The fabricated stimulators were experimentally evaluated prior to implantation. The voltage and current across the PZT was measured using an Agilent DSO6014A oscilloscope and Tektronix CT1 (1 GHz) current probe, respectively. The power dissipated by the PZT is given by

$$
P_{c}=V_{\mathrm{rms}} I_{\mathrm{rms}} \cos (\varphi),
$$

where $I$ is the current flowing through PZT, $V$ is the drive voltage and $\varphi$ is the phase difference between the current and the drive voltage. The temperatures in the experiments were measured using a K-type thermocouple read using an HH506A multilogger thermometer.

The experiments were carried out using a PZT-5A heater (P1) bonded to an elytra of a beetle carcass. The existence

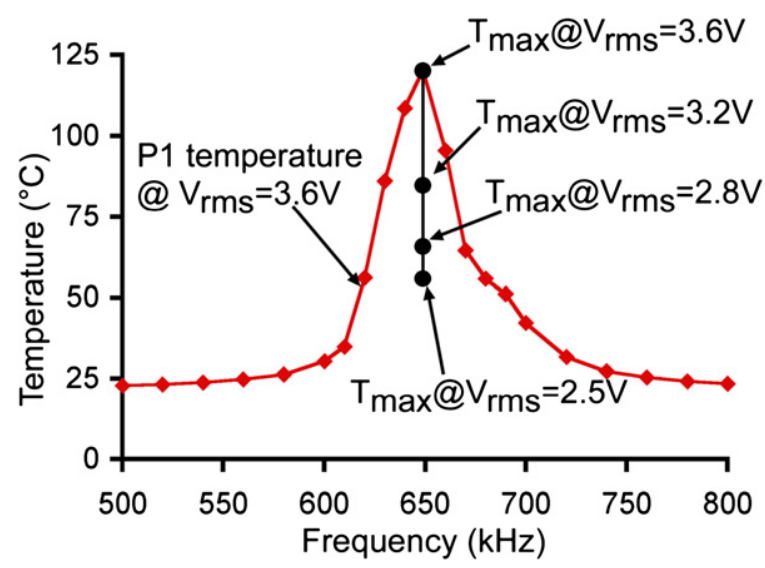

Figure 5. Variation of the steady state temperature attained by the piezothermal stimulator as a function of frequency when bonded to the elytra of the beetle. The temperature variation with the input RMS voltage is also plotted.
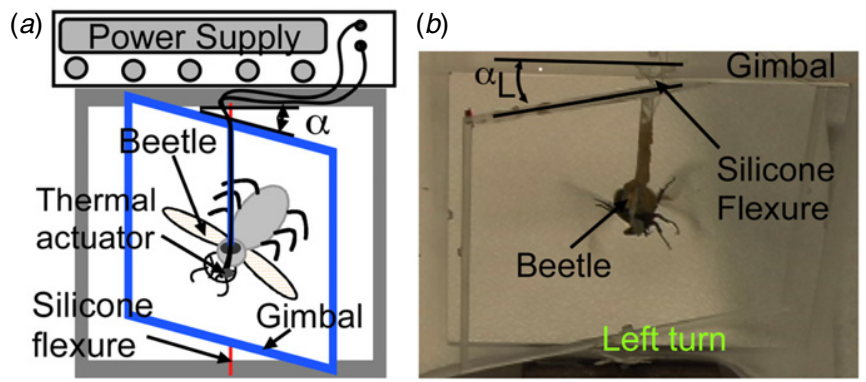

Figure 6. (a) Schematic of the experimental setup used in characterizing the angle turned by the beetle. (b) Photograph of a beetle turning toward its left side due to actuation on its right side.

of an optimal operating frequency for P1 is evident from the peak in figure 5. This frequency corresponds to the resonance frequency $(650 \mathrm{kHz})$ of the structure (PZT bonded to beetle) measured using the impedance analyzer (Agilent 4395A). The frequency at which the maximum temperature $(650 \mathrm{kHz})$ was attained was then further used to study the steady state response of the piezothermal stimulator at varying input voltages (figure 5). It was thus determined that at this frequency, P1 achieved a thermal efficiency of $0.93{ }^{\circ} \mathrm{C} \mathrm{mW}^{-1}$. The thermal time constant of the stimulators (used in this work), when bonded to the elytra of a beetle carcass, varied between 6 and $11 \mathrm{~s}$.

\subsection{Insect locomotion experiments}

3.2.1. Experimental methods. Experiments were conducted on GJBs, Madagascar hissing roaches and GDBs in order to show the versatility of the proposed technique. For the experiments on GJBs, the response of the beetles to thermal stimulation was quantified by attaching them to a custom fabricated gimbal with an acrylic frame and silicone flexures (figure 6(a)). The gimbal was designed to minimize resistance to rotation about its axis, while constraining the other degrees of freedom. The torsional stiffness of the silicone flexures was experimentally measured at $68.7 \mathrm{mN} \mathrm{mm} \mathrm{rad}{ }^{-1}$. The performance of P3 PZT stimulators $\left(1 \times 0.5 \times 0.127 \mathrm{~mm}^{3}\right)$ 


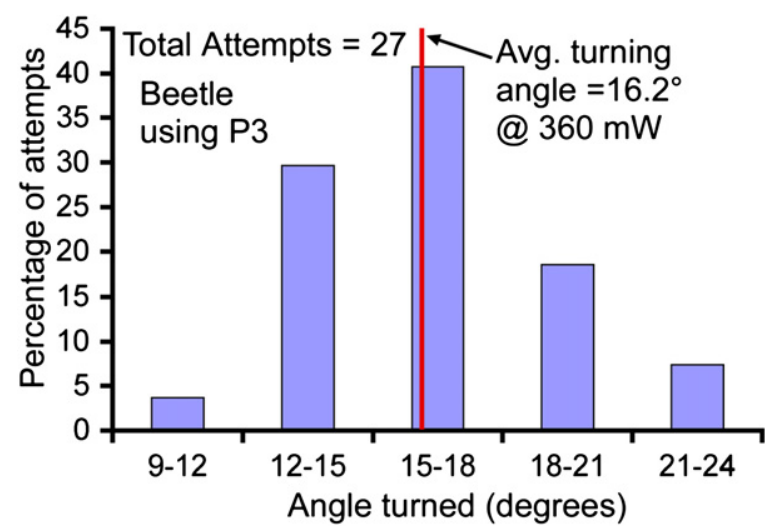

Figure 7. Turning characterization for $\mathrm{P} 3$ in GJB. $\mathrm{P} 3$ produces an average turning of $16^{\circ}$ at $360 \mathrm{~mW}$.

was compared with that of a resistive stimulator. These ' $\mathrm{V}$ '-shaped $\mathrm{Ni}$ foil stimulators (R1) of size $4 \times 1.3 \times$ $0.05 \mathrm{~mm}^{3}$ were fabricated using a photochemical etching process (Fotofab Corporation, Chicago, IL, USA). The stimulators R1 were bonded to the beetle head using epoxy to prevent being dislodged by the beetle. The stimulators P3 were implanted into the head of the beetle near the antennae. An ac function generator (HP 33520A) was used to actuate the PZT stimulators. A dc power supply (HP E3630A) was used to actuate the resistive stimulators. The stimulators, P3, were actuated at the resonance frequency $(1.9 \mathrm{MHz})$ for maximum thermal efficiency.

For the experiments on the roaches, two sets of PZT-based stimulators, P1 (3.2 mm diameter and $0.191 \mathrm{~mm}$ thickness) and P2 $\left(3 \times 1 \times 0.127 \mathrm{~mm}^{3}\right)$, were investigated. The roaches were tested with two PZT stimulators implanted on either side of the thorax, but near the head (figure 1). The turning responses were characterized by performing the tests on a surface marked with angles (figure 8). An ac function generator (Agilent 33250A) was used to actuate P1 and P2 stimulators at their respective resonance frequencies of 4.2 and $5.5 \mathrm{MHz}$, respectively.

For the experiments on GDBs, the PZT stimulators were again implanted in the thorax of the beetles (figure 1). The locomotion of the beetles was monitored within a water-filled container. The PZT stimulators, P4 (diameter $200 \mu \mathrm{m}$ and thickness $40-50 \mu \mathrm{m}$ ), were used in these experiments because GDBs were smaller in size compared to other two types of insects. Because of the smaller size of these stimulators, the impedance is relatively high. This limits the current flowing through the stimulator, particularly at lower frequencies which in turn limits the heat generated by these stimulators at a given voltage amplitude. The maximum voltage that can be applied to these stimulators is limited by the depoling electric field of the PZT $\left(7 \mathrm{kV} \mathrm{cm}^{-1}\right.$ for PZT-5A) and the function generator. Hence, in order to generate enough heat, the stimulators were operated at a higher order resonance mode (44-47 MHz).

3.2.2. Results from GJB. The GJB has active flight behavior and appreciable load capacity, which are appealing characteristics for transporting sensor platforms (figure 1) [40].

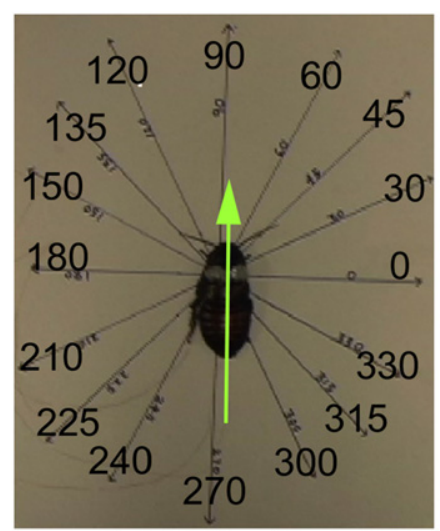

Initial Position

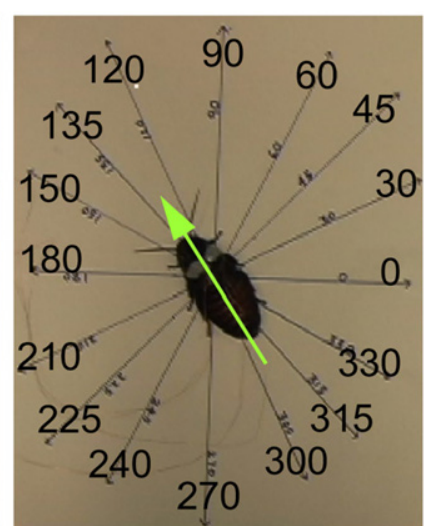

Final Position
Figure 8. Photograph of the roach turning toward its left side due to the actuation of $\mathrm{P} 2$ on the right side. The angle turned was characterized by positioning the roach on the paper marked with angles.

It has been observed that the head of the beetle is the most sensitive location for thermal stimulation, particularly in the vicinity of the antennae [41]. Hence, in these experiments, the thermal stimulators are attached or implanted near the antennae of the beetles.

Experimental results confirmed the aversion of beetle to thermal stimulation. The micro-stimulators, R1 and P3, repeatedly demonstrated initiation of flight and change in direction of the GJB. The beetles turned away from the direction of the actuated stimulator (figure $6(b)$ ). The restoring torque exerted by the gimbal on the beetle resulted in a steady state final orientation of the beetle during flight. The turning angle was measured as the difference between the final steady state orientation and the initial orientation of the beetle. The beetles returned to the initial orientation once the flight ceased. An applied power of $800 \mathrm{~mW}$ across R1 resulted in the stimulation of the beetle. This confirmed that the thermal response was indeed the cause of stimulation. The beetle turned away from the side being stimulated by approximately $15^{\circ}(0.26 \mathrm{rad})$, which resulted in a torque of $18 \mathrm{mN} \mathrm{mm}$. However, stimulator P3 required only $360 \mathrm{~mW}$ of power for flight initiation and direction guidance. Table 3 lists the data on experiments performed in individual GJB using P3. The success rate varied between $75 \%$ and $83.33 \%$. The statistical results for repeated actuation of P3 for insect 3 are plotted in figure 7. The beetle rotated away from the side being stimulated by an average $16.2^{\circ}$ which demanded a torque of $19.2 \mathrm{mN} \mathrm{mm}$. On average, the time required for stimulation was $55 \mathrm{~s}$ at an input power level of $360 \mathrm{~mW}$. The statistical variations between the left and right turns were also measured. The $p$-value measured using Student's $t$-test was 0.85 .

3.2.3. Results from Madagascar hissing roaches. In order to show the versatility of the proposed technique, experiments were also performed on Madagascar hissing roaches. The roaches are known to be resistant to radiation making it an ideal candidate for micro vehicle applications [42].

Figure 8 shows a sample consequence of stimulating the right side of the roach. Like beetles, the roach also turned 


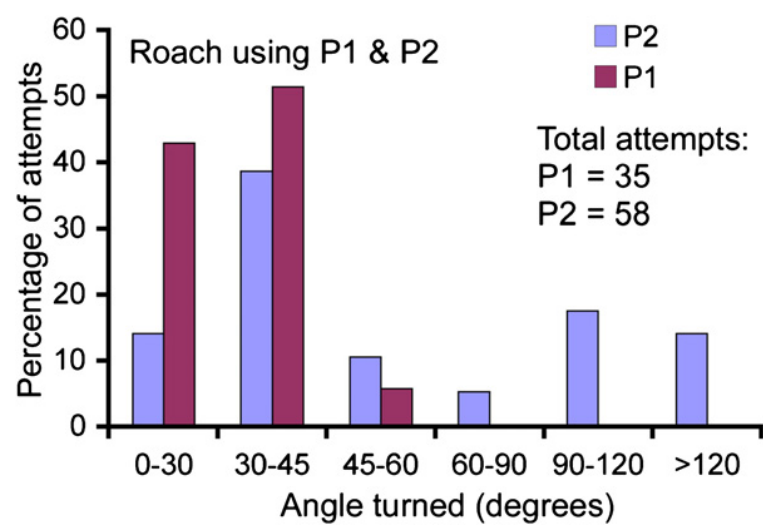

Figure 9. Turning characterization for $\mathrm{P} 1$ and $\mathrm{P} 2$ in roaches. Statistical variation of angle turned indicates that the maximum count occurs in the range of $30^{\circ}-45^{\circ}$ per actuation at $330 \mathrm{~mW}$.

Table 3. Data on experiments performed in individual GJB using P3. The table lists the total number of attempts $(N)$, success rate, average turn angle and standard deviation of the turn angle in individual experiments.

\begin{tabular}{lrlll}
\hline Insect & $N$ & Success $\%$ & Avg. turn angle & Std dev. turn angle \\
\hline 1 & 6 & 83.33 & - & - \\
2 & 16 & 75 & - & - \\
3 & 34 & 80 & $16.2^{\circ}$ & $2.93^{\circ}$ \\
4 & 5 & 80 & $13.7^{\circ}$ & $2.06^{\circ}$ \\
\hline
\end{tabular}

Table 4. Data on experiments performed in individual Madagascar hissing roaches. The table lists the stimulator used, total number of attempts $(N)$, success rate, average turn angle and standard deviation of the turn angle in individual experiments.

\begin{tabular}{llllll}
\hline Insect & Stim. & $N$ & Success\% & $\begin{array}{l}\text { Avg. turn } \\
\text { angle }\end{array}$ & $\begin{array}{l}\text { Std dev. } \\
\text { turn angle }\end{array}$ \\
\hline 1 & P1 & 60 & 60 & $31.8^{\circ}$ & $8.17^{\circ}$ \\
2 & P1 & 34 & 76.4 & $46.73^{\circ}$ & $26.97^{\circ}$ \\
3 & P2 & 16 & 93.75 & $50^{\circ}$ & $18.29^{\circ}$ \\
4 & P2 & 20 & 90 & $34.2^{\circ}$ & $10.23^{\circ}$ \\
6 & P2 & 62 & 93.5 & $64.47^{\circ}$ & $43^{\circ}$ \\
\hline
\end{tabular}

away from the activated stimulator. The roaches either jerked to the side, away from the stimulator, or turned away from the side being stimulated and moved some distance. Hence in the experiments, the angle turned was measured once the roach had stopped turning. The minimum power required for the actuation using P1 was about $550 \mathrm{~mW}$; P2 required only about $330 \mathrm{~mW}$, mainly due to its smaller thermal mass. Table 4 lists the data from P1 and P2 used separately. The P2 stimulators showed superior direction guidance: $90-93.75 \%$ of total attempts were successful as compared to $60-76.4 \%$ for P1. This was also attributed to the smaller size of P2 which makes localized heating possible. The angle turned during each stimulation event was characterized for both the PZT heaters for insects 1 and 6 (figure 9). The roaches turn about $30^{\circ}-45^{\circ}$ per stimulation. As expected, the left and right turns were statistically similar (figure 10). The $p$-value measured using Student's $t$-test was 0.64 .

The variation in the time needed for actuation with applied power was studied using P2. On average, about $20 \mathrm{~s}$ were

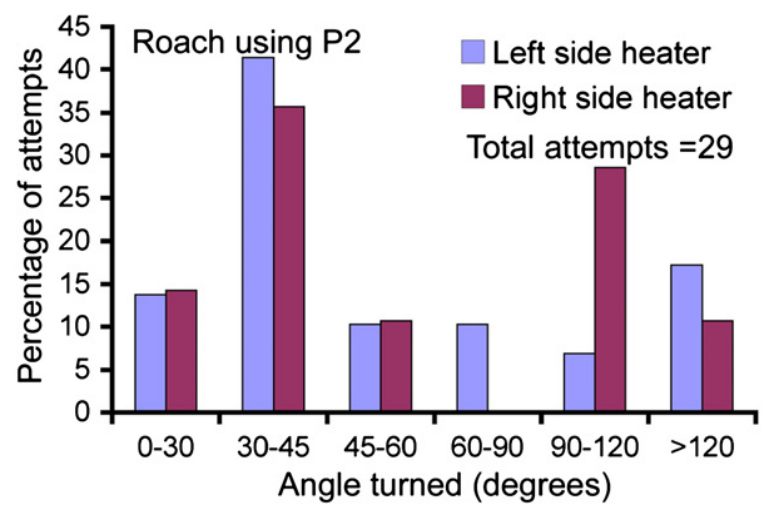

Figure 10. Left and right turning characteristics for $\mathrm{P} 2$ in roaches. The behavior was statistically symmetrical.

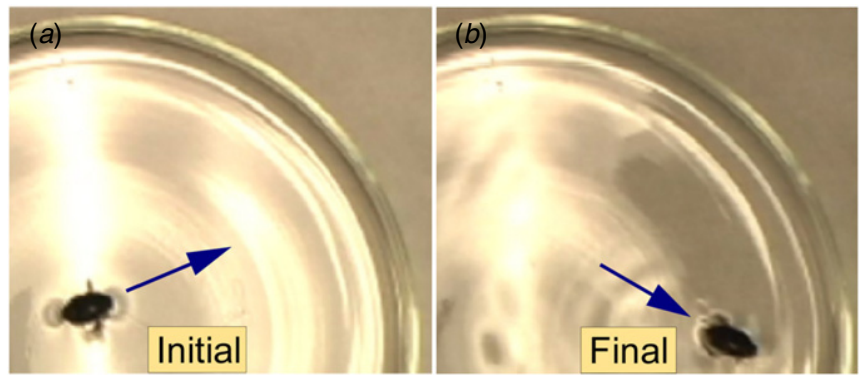

Figure 11. Photograph of the GDB turning towards its right side due to stimulation on the left side. The arrow indicates the orientation of the GDB before and after stimulation.

needed for stimulation at an input power of $400 \mathrm{~mW}$. It was observed that the time for actuation generally decreased as the input power increased.

\subsubsection{Results from GDBs. Experiments were conducted} on GDBs to show the applicability of thermal stimulation for locomotion training of aquatic insects. The GDBs are oval in shape and are generally $\frac{3}{4}$ inches long. The GDBs have oarshaped rear legs with hair-like structures to assist in swimming. Unlike other aquatic insects, GDBs generally travel on or near the surface of water.

Figure 11 shows a sample response of a GDB to the actuation of the left-side stimulator. Like the other insects, the GDBs turned away from the thermal stimulation. Table 5 lists the data on experiments performed in individual GDBs using P4. The GDBs were more active as compared to other two species. The insects moved in certain trials even though there was no stimulation. Hence, the statistical variation in the response of the insect with and without stimulation was measured. The results obtained for insect 2 are shown in figure 12. The GDBs did not move for $90 \%$ of the attempts when there was no stimulation. The GDBs turned in $66.67 \%$ of the attempts when the stimulator was actuated. When the GDBs were stimulated the insects moved and turned simultaneously, and attained a steady state orientation. The angle was measured between the final orientation and the initial orientation of the insect. The angle of the turns was typically $30^{\circ}-50^{\circ}$. A difference was observed in the statistical 


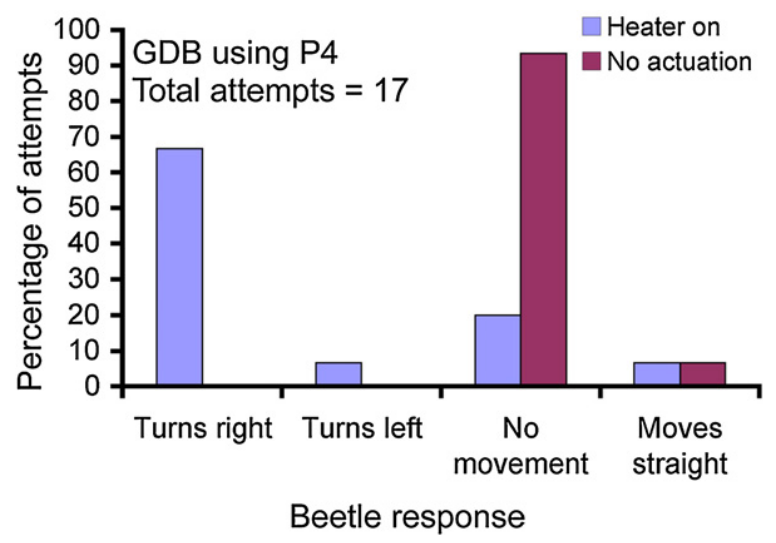

Figure 12. Statistical variation of the response of the GDBs with and without thermal stimulation.

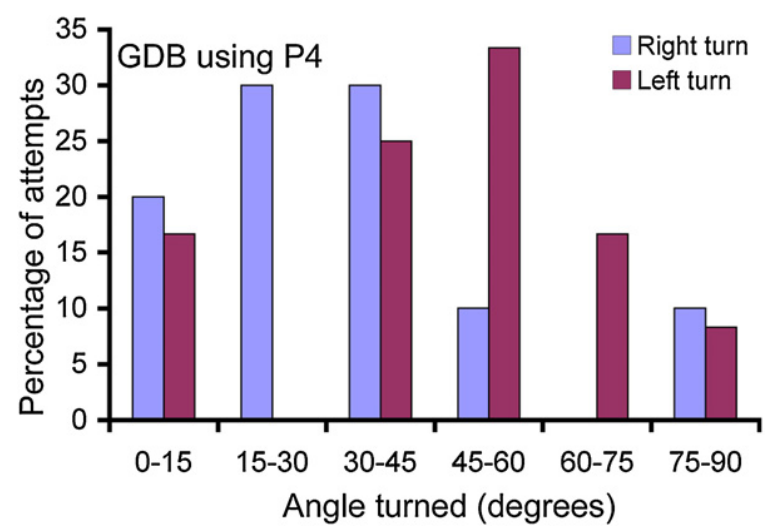

Figure 13. Left and right turning characteristics for P4 in GDBs. The GDBs turn about $15^{\circ}-60^{\circ}$ per actuation.

Table 5. Data on experiments performed in individual GDBs using P4. The table lists the total number of attempts $(N)$, success rate, average turn angle and standard deviation of the turn angle in individual experiments.

\begin{tabular}{lrlll}
\hline Insect & $N$ & Success\% & $\begin{array}{l}\text { Avg. turn } \\
\text { angle }\end{array}$ & $\begin{array}{l}\text { Std dev. } \\
\text { turn angle }\end{array}$ \\
\hline 1 & 13 & 53.84 & $35.8^{\circ}$ & $12.37^{\circ}$ \\
2 & 15 & 66.67 & $34^{\circ}$ & $22.46^{\circ}$ \\
3 & 8 & 62.5 & $21^{\circ}$ & $12.18^{\circ}$ \\
4 & 36 & 61.1 & $34.4^{\circ}$ & $25.98^{\circ}$ \\
5 & 14 & 64.28 & $46.8^{\circ}$ & $25.98^{\circ}$ \\
\hline
\end{tabular}

variation in the turning angles between the right-side and leftside stimulation (figure 13). On average, the angles turned during the right-side and left-side stimulation were $30^{\circ}-60^{\circ}$ and $15^{\circ}-45^{\circ}$, respectively. This lack of symmetry is attributed to the force exerted by the connecting wires on the GDB. This was not observed on other insect species, which were larger in size as compared to GDBs. The statistical variations between the left and right turns were also measured. The $p$-value measured using Student's $t$-test was 0.27. Within a water ambient, the average input power required for stimulation was $100 \mathrm{~mW}$. At this input power, the average time for stimulation was measured to be $78 \mathrm{~s}$.

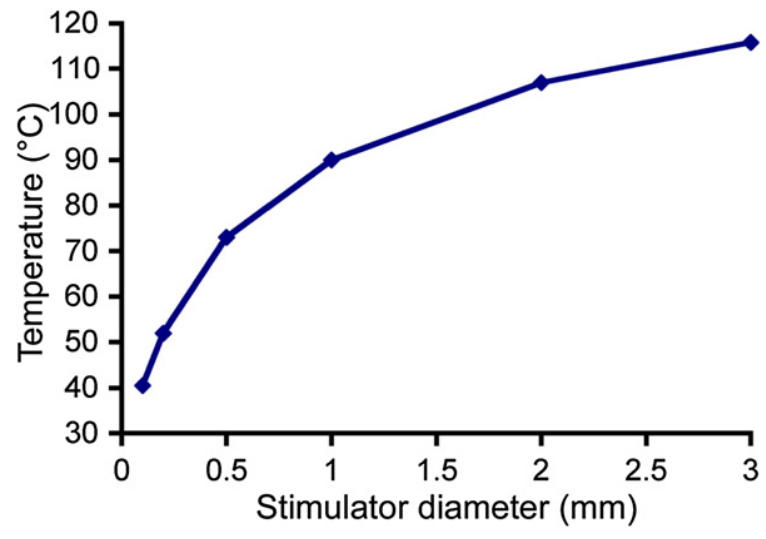

Figure 14. The average temperature at the tissue-stimulator interface for different sizes of the piezothermal stimulator when the maximum temperature in the stimulator is $450 \mathrm{~K}$. Simulations suggest that for diameter $<130 \mu \mathrm{m}$, the interface temperature falls below $43{ }^{\circ} \mathrm{C}$.

\section{Discussion}

\subsection{Scaling of piezothermal stimulators}

Reducing the size of the stimulator is attractive because this reduces the total heat delivered in each stimulation and also localizes the stimulation for better directional response. It also reduces the power required for achieving the target temperature of $43{ }^{\circ} \mathrm{C}$. However, the smallest size of the stimulator is limited by the maximum allowable temperature in the PZT stimulator. Even though the stimulator size is scaled down, the thickness of the connecting wire and insulating epoxy remain constant for reliable operation of the device. Hence, the maximum temperature within the stimulator increases for a given interface temperature as we shrink the size of the stimulator. The maximum allowable temperature in the PZT is limited to $50 \%$ of the Curie temperature. For PZT-5A, the temperature is limited to $450 \mathrm{~K}$ (for $T_{\text {curie }}=350{ }^{\circ} \mathrm{C}$ ).

Finite element simulations were performed for different diameters of the $125 \mu \mathrm{m}$ thick circular PZT stimulator to determine the average temperature at the tissue interface when the maximum temperature in the stimulator reaches $450 \mathrm{~K}$. The properties of the heaters, connecting wires and insulating epoxy used in the simulations are listed in table 1. Figure 14 suggests that the minimum diameter is $130 \mu \mathrm{m}$, below which the temperature at the stimulator-tissue interface falls below $43{ }^{\circ} \mathrm{C}$.

\section{Conclusions}

The locomotion response of insects to thermal stimulation using microheaters was studied. Experiments conducted on GJBs, Madagascar hissing roaches and GDBs suggested the feasibility of locomotion initiation and direction change in the insects by microthermal stimulation. Further, piezothermal stimulation especially near the resonance frequency was observed to be more power efficient. The PZT-based stimulators achieved a thermal efficiency of $0.93{ }^{\circ} \mathrm{C} \mathrm{mW}^{-1}$ when bonded to the elytra of a beetle. A finite element 
model was used to estimate the required power for the beetlestimulator interface temperature to be $43{ }^{\circ} \mathrm{C}$ (required for stimulation). The piezothermal stimulation showed an overall success rate of $78.7 \%, 92.8 \%$ and $61.6 \%$ on GJBs, Madagascar hissing roaches and GDBs, respectively. On average, thermal stimulation resulted in an angle turn of about $13.7^{\circ}-16.2^{\circ}$ on GJBs, $30^{\circ}-45^{\circ}$ on the roaches and $30^{\circ}-50^{\circ}$ on GDBs. The corresponding average input power was 360, 330 and 100 $\mathrm{mW}$ for GJBs, roach and GDBs, respectively. The range of motion and the power efficiency available from electroneural stimulation are generally superior. However, PZT stimulators may be effective as a generalized stimulation method for locomotion guidance and operant training of wide variety of insects, and as a method that accommodates coarse positioning of stimulus.

\section{Acknowledgments}

The authors would like to thank Professor Michel M Maharbiz and Dr Naveen Kumar Gupta for valuable suggestions and discussions. The authors would also like to thank Dr Hirotaka Sato for help in rearing of beetles and Mr Ethem Erkan Akatakka for certain microfabrication steps. This study is supported in part by Defense Advanced Research Projects Agency Microsystems Technology office (DARPAMTO). KV acknowledges partial support by a fellowship from the Mechanical Engineering Department at University of Michigan.

\section{References}

[1] Ashley S 1998 Palm-size spy planes ASME J. Mech.Eng. 120 74-8

[2] Greek D 1999 Prototype for a micro air vehicle Prof. Eng. 12 26

[3] Kellogg J et al 2002 The NRL micro tactical expendable (MITE) air vehicle Aeronaut. J. 106 431-41

[4] Ifju P G, Jenkins D A, Ettinger S, Lian Y, Shyy W and Waszak M R 2002 Flexible wing based micro air vehicle Proc. Am. Inst. Aeronaut. Astronaut. AIAA Paper 2002-0705

[5] Morris R S and Holden M 2000 Design of micro air vehicles and flight test validation Proc. Fixed, Flapping and Rotary Wing Vehicles at Very Low Reynolds Numbers pp 153-76

[6] Patel C, Arya H and Sudhakar K Design, build and fly a solar powered aircraft Indian Institute of Technology, Mumbai, India (http://www.casde.iitb.ac.in/Publications/pdfdoc/ solar-AeSI-AGM.pdf)

[7] Michelson R C and Reece S 1998 Update on flapping wing micro air vehicle research 13 th Bristol Int. RPV Conf. (Bristol, UK)

[8] Pornsin-sirirak T N, Tai Y C, Nassef H and Ho C M 2001 Titanium alloy MEMS wing technology for a micro aerial vehicle application Sensors Actuators A 89 95-103

[9] De Croon G C H E, De Clerq K M E, Ruijsink R, Remes B and De Wagter C 2009 Design, aerodynamics, and vision based control of the DelFly Int. J. Micro Air Veh. 1 71-97

[10] Yan J, Wood R, Avadhanula S, Sitti M and Fearing R 2001 Towards flapping wing control for a micromechanical flying insect IEEE Int. Conf. on Robotics and Automation (Seoul, Korea) pp 253-62

[11] Wood R J 2008 The first takeoff of a biologically inspired at-scale robotic insect IEEE Trans. Robot. 24 341-7
[12] Bachmann R J, Boria F J, Vaidyanathan R, Ifju P G and Quinn R D 2009 A biologically inspired micro-vehicle capable of aerial and terrestrial locomotion Mech. Mach. Theory 44 513-26

[13] Guo S, Ge Y, Li L and Liu S 2006 Underwater swimming micro robot using IPMC actuator IEEE Int. Conf. on Mechatronics and Automation pp 249-54

[14] Guo S, Shi L and Asaka K 2008 IPMC actuator-based an underwater microrobot with 8 legs IEEE Int. Conf. on Mechatronics and Automation pp 551-6

[15] Sato H and Maharbiz M M 2010 Recent developments in the remote radio control of insect flight Frontiers Neurosci. 4199

[16] Hausen K and Wehrhahn C 1989 Neural circuits mediating visual flight control in flies: I. Quantitative comparison of neural and behavioural response characteristics $J$. Neurosci. $93828-36$

[17] Hausen K, C and Wehrhahn 1990 Neural circuits mediating visual flight control in flies: II. Separation of two control systems by microsurgical brain lesions J. Neurosci. $10351-60$

[18] Sane S P, Dieudonne A, Willis M A and Daniel T L 2007 Antennal mechanosensors mediate flight control in moths Science 315 863-6

[19] Kuwana Y, Ando N, Kanzaki R and Shimoyama I 1999 A radiotelemetry system for muscle potential recordings from freely flying insects Proc. 1st Joint BMES/EMBS Conf. Serving Humanity, Advancing Technology (Atlanta, GA, USA) p 846

[20] Takeuchi S and Shimoyama I 2004 A radio-telemetry system with a shape memory alloy microelectrode for neural recording of freely moving insects IEEE Trans. Biomed. Eng. 51 133-7

[21] Mohseni P, Nagarajan K, Ziaie B, Najafi K and Crary S B 2001 An ultralight biotelemetry backpack for recording EMG signals in moths IEEE Trans. Biomed. Eng. $48734-7$

[22] Moore T E, Crary S B, Koditschek D E and Conklin T A 1998 Directed locomotion in cockroaches: biobots Acta Entomol. Slovenica 6 71-8

[23] Kuwana Y, Watanabe N, Shimoyama I and Miura H 1994 Behavior control of insects by artificial electrical stimulation Distrib. Robot. Auton. Syst. 291-302

[24] Holzer R and Shimoyama I 1997 Locomotion control of a bio-robotic system via electric stimulation IEEE/RSJ Int. Conf. on Intelligent Robots and System (Grenoble, France) pp 1514-9

[25] Bozkurt A, Gilmour R, Stern D and Lal A 2008 MEMS based bioelectronic neuromuscular interfaces for insect cyborg flight control 21st IEEE Int. Conf. on Micro Electro Mechanical Systems (Tuscan) pp 160-3

[26] Graetzel C F, Medici V, Rohrseitz N, Nelson B J and Fry S N 2008 The cyborg fly: a biorobotic platform to investigate dynamic coupling effects between a fruit fly and a robot IEEE/RSJ Int. Conf. on Intelligent Robots and Systems (Nice, France) pp 14-9

[27] Sato H, Berry C W, Casey B E, Lavella G, Yao Y, VandenBrooks J M and Maharbiz M M 2008 A cyborg beetle: insect flight control through an implantable tetherless microsystem 21 st IEEE Int. Conf. on Micro Electro Mechanical Systems (Tuscan) pp 164-7

[28] Sato H, Berry C W and Maharbiz M M 2008 Flight control of 10 gram insects by implanted neural stimulators Solid-State Sensor \& Actuator Workshop (Hilton Head, SC) pp 90-1

[29] Yager D D and Spangler H G 1997 Behavioral response to ultrasound by the tiger beetle Cicindela marutha Dow combines aerodynamic changes and sound production J. Exp. Biol. 200 649-59 
[30] Paul A, Bozkurt A, Ewer J, Blossey B and Lal A 2006 Surgically implanted micro-platforms in Manduca sexta moth Solid-State Sensor \& Actuator Workshop (Hilton Head, SC) pp 209-11

[31] Sato H, Peeri Y, Baghoomian E, Berry C W and Maharbiz M M 2009 Radio controlled cyborg beetles: a radio frequency system for insect neural flight control $21 \mathrm{st}$ IEEE Int. Conf. on Micro Electro Mechanical Systems (Hilton Head, SC) pp 216-9

[32] Sato H, Berry C W, Peeri Y, Baghoomian E, Casey B E, Lavella G, VandenBrooks J M, Harrison J F and Maharbiz M M 2009 Remote radio control of insect flight Front. Integr. Neurosci. 324

[33] Brembs B 2008 Operant learning of Drosophila at the torque meter J. Vis. Exp. 16 doi:10.3791/731 (http://www.jove.com/details.php?id=731)

[34] Visvanathan K, Gupta N K, Maharbiz M M and Gianchandani Y B 2008 Flight initiation and directional control of beetles by microthermal stimulation Solid-State Sensors and Actuators and Microsystems Workshop (Hilton Head Island, SC) pp 126-9

[35] Visvanathan K, Gupta N K, Maharbiz M M and Gianchandani Y B 2009 Control of locomotion in ambulatory and airborne insects using implanted thermal microstimulators IEEE Int. Conf. on Solid-State Sensors,
Actuators, and Microsystems (Transducers) (Denver, CO) pp 1987-90

[36] Abaraw M 2005 An introduction to thermal remediation from TEMP-AIR: a patented process to eliminate pests with dry, clean heat: an effective, safe and economical alternative to methyl bromide Annual Int. Conf. on Methyl Bromide Alternatives and Emissions Reductions

[37] Liang C, Sun F and Rogers C A 1996 Electro-mechanical impedance modeling of active material systems Smart Mater. Struct. 5 171-86

[38] Zhou S W and Rogers C A 1995 Heat generation, temperature, and thermal stress of structurally integrated piezo-actuators J. Intell. Mater. Syst. Struct. $6372-9$

[39] Li T and Gianchandani Y B 2006 A micromachining process for die-scale pattern transfer in ceramics and its application to bulk piezoelectric actuators J. Microelectromech. Syst. 15 605-12

[40] Domek J M and Johnson D T 1988 Demonstration of semiochemically induced aggregation in green June beetle, Cotinis nitida Environ. Entomol. 17 147-9

[41] Gullan P J and Cranston P 2004 The Insects: An Outline of Entomology (Oxford: Blackwell) pp 85-111

[42] http://www.thebigzoo.com/Animals/ Madagascar_Hissing_Cockroach.asp 